\title{
Vanguardia y violencia en el Cono Sur: Bolaño relee a Arlt
}

\author{
Vanguard and Violence in the Southern Cone: Bolaño Rereads Arlt \\ Vanguarda e violência no Cone Sul: Bolaño relê a Arlt
}

\section{Luis H. Castañeda}

MIDDLEBURY COLLEGE, ESTADOS UNIDOS

Profesor en Middlebury College, Estados Unidos. PhD en Español,

Universidad de Colorado en Boulder. Autor de la monografía

Comunidades efímeras: grupos de vanguardia y neovanguardia en

la novela hispanoamericana del siglo $X X$ (Nueva York: Peter Lang,

2015), "Luis Loayza y el canon de la literatura peruana: condición

colonial, ética literaria y forma ensayística en El sol de Lima" (Revista

hispánica moderna 67.1 (2014): 1-16), "El fracaso del mal: Damas

chinas de Mario Bellatin", Salón de anomalías: diez lecturas críticas

acerca de la obra de Mario Bellatin (Lima: Ediciones Altazor, 2013),

"La boca de la sierpe, la quijada del león: (in)moralidad, verdad

intraverbal y diseminación en los Sueños de Quevedo" (Romance

Quarterly 60.4, 2013), "Una dispersa dinastía de solitarios: la sociedad

secreta en los cuentos de Borges" (Variaciones Borges 32 (2011):

179-200), "Personas fidedignas y palabras formales: estrategias de

legitimación del narrador historiográfico en la cuarta parte de la

Crónica del Perú de Pedro Cieza de León" (Hispanic Review $79 \cdot 3$

(2011): 399-423). Correo electrónico: lcastaneda@middlebury.edu

Artículo de reflexión

Este artículo es la versión extensa de un trabajo presentado en una conferencia ("The Copper Rose and the Secret Society: Roberto Arlt's Vanguardist Project in The Seven Madmen/The Flamethrowers". 2013 Convention of the Rocky Mountain Modern Language Association. Vancouver, Washington. October 10-12, 2013.

Documento accesible en línea desde la siguiente dirección: http://revistas.javeriana.edu.co

doi: 10.11144/Javeriana.cl20-39.vvcs 


\section{Resumen}

Este artículo discute la intersección entre vanguardismo y violencia en las obras de Roberto Arlt (El juguete rabioso, Los siete locos/Los lanzallamas) y Roberto Bolaño (Estrella distante). Se empieza por inscribir a Arlt en un vanguardismo caracterizado por la naturaleza violenta y criminal de la fusión vanguardista del arte y la vida. A continuación se analiza, en la novela de Bolaño, la recontextualización neovanguardista y la evaluación ética del vanguardismo arltiano. El artículo concluye afirmando la persistencia, matizada por la autoconciencia crítica, de un "vanguardismo de la violencia" en la literatura del Cono Sur.

Palabras clave: vanguardismo (literatura), literatura argentina, literatura chilena, Roberto Arlt, Roberto Bolaño, violencia

\section{Abstract}

This article discusses

the intersection between

vanguardism and violence in

the works of Roberto Arlt ( $E l$

Fuguete Rabioso, Los Siete Locos/

Los Lanzallamas) and Roberto

Bolaño (Estrella Distante). We

start by subscribing Arlt to a

vanguardism characterized by

the violent and criminal nature of the vanguardist fusion of art and life. Then we analyze, in Bolaño's novel, the neo-vanguardist recontextualization and the ethical evaluation of Arlt's vanguardism. The article concludes stating the persistence, tinged by a critical self-awareness, of a "vanguardism of violence" in the literature of the Southern Cone.

Keywords: vanguardism (literature); Argentinian literature; Chilean literature; Roberto Arlt; Roberto Bolaño; violence

\section{Resumo}

Este artigo discute a intersecção entre vanguardismo e violência nas obras de Roberto Arlt (El juguete rabioso, Los siete locos/Los lanzallamas -o brinquedo raivoso, os sete malucos/os lança-chamas) e Roberto Bolaño (Estrella distante-Estrela distante). Começa-se por inscrever a Arlt em um vanguardismo caraterizado pela natureza violenta e criminosa da fusão vanguardista de arte e vida. Em seguida analisa-se, no romance de Bolaño, a recontextualização neovanguardista e a avaliação ética do vanguardismo arltiano. $\mathrm{O}$ artigo conclui afirmando a persistência, temperada pela autoconsciência crítica, de um "vanguardismo da violência" na literatura do Cone Sul.

Palavras-chave: vanguardismo (literatura); literatura argentina; literatura chilena; Roberto Arlt; Roberto Bolaño; violência

\section{Cómo citar este artículo:}

Castañeda, Luis H. "Vanguardia y violencia en el Cono Sur: Bolaño relee a Arlt". Cuadernos de Literatura 20.39 (2016): 312-337. http://dx.doi.org/10.11144/Javeriana.cl20-39.vvcs 
LA PREGUNTA POR la vigencia de la vanguardia en el presente suele conducir al choque entre dos discursos: el de la vitalidad y el del agotamiento. En primer término, la retórica del agotamiento reitera el fin del paradigma vanguardista y juega con cierta nostalgia por una edad mítica de radicalismo estético-político aparentemente perdido en la década de 2010. Por contraste, rechazando el fin de las utopías, el discurso vitalista anuncia el seguimiento, el reciclamiento o el (re) surgimiento de la vanguardia en algunas formas experimentales del arte y la literatura contemporáneos. En un artículo reciente, Julio Premat sintetiza la polémica como un debate entre dos figuras emblemáticas del pensamiento teórico sobre la vanguardia: Peter Bürger como heraldo del final y Hal Foster como mensajero de la continuidad (63). El juicio de que la industrialización neovanguardista del shock supone la muerte y la degeneración de las escuelas más renovadoras de la vanguardia histórica, que se desarrolla en Teoría de la vanguardia de 1974 (Bürger 74-77), halla su contrapunto en la visión contraria de Foster en El retorno de lo real (1996), según la cual las neovanguardias europea y norteamericana de 1950-1960 reelaboran y, de hecho, profundizan el legado vanguardista clásico, tornándolo potencialmente interminable y original en cada nueva iteración (Foster 8-20).

Por su parte, Premat se inclina por la visión de Foster para sugerir que, en la estética del siglo XXI y, en particular, en la literatura, "se puede ser vanguardista de cara al pasado" (56). Esta fórmula no resulta paradójica si se considera que nuestra concepción de la historia — vacila Premat en describirla como posmoderna, pero afirma su tendencia al relativismo - sospecha de las narraciones lineales y de la teleología del progreso, tan cara a los defensores del "arte nuevo", haciendo posible una reconfiguración de la temporalidad del presente y un retorno no anacrónico de la memoria ${ }^{1}$. En este artículo miro también hacia el pasado pero sin despegarme del presente, para encontrar el sentido de cierto inquietante filón de la literatura producida en el Cono Sur a fines del siglo XX; en concreto, reconsidero la alianza entre violencia y vanguardia patente en las novelas de Roberto Arlt, con el fin de contextualizar la revitalización del ethos vanguardista que se manifiesta en la novelística de Roberto Bolaño, en la que la violencia es también

1 Premat se concentra en los casos de los argentinos César Aira, Damián Tabarovsky y Marcelo Cohen, y el mexicano Mario Bellatin, como escritores que resemantizan la "vanguardia" latinoamericana. Plantea, siguiendo a Sandra Contreras en Las vueltas de César Aira, que en la obra de Aira "se trata de 'empezar de nuevo' las vanguardias, no como una autocrítica de la institución, sino como 'reinvención' del proceso artístico" (Premat 49). La dimensión de autocrítica, principalmente ética, parece estar más presente en Bolaño que en Aira, como se ve en las páginas siguientes. 
un problema esencial y urgente. Propongo, en suma, que la vanguardia encuentra en Bolaño un suspicaz continuador ${ }^{2}$.

Una primera consideración a ofrecer es que la obra narrativa de Arlt postula una modulación particularmente violenta y destructiva del llamado vanguardista a "estetizar" la vida, modulación que, según intento demostrar, aún hoy deja sentir su huella entre nuestros creadores. En Arlt, "estetizar" la vida implica aniquilarla cinematográficamente, montar un espectáculo de horror y muerte, aunque dicha liquidación se da siempre al interior de un régimen de representación simulado (Baudrillard 7) en el cual el discurso violentista se libera de su referente, logrando así, mediante su alejamiento de la realidad objetiva, esquivar una reflexión sobre sus implicancias éticas. La violencia de Arlt posee un doble rostro, tanto literal como simbólico: primero, como una fuerza letal, declarada en actos como el asesinato; y, segundo, como un impulso derribador de murallas o como una especie de puente en llamas que comunica las esferas de la experiencia y de la belleza. En la obra de Bolaño se retoma, desde otras premisas literarias y sin necesidad de hacer alusión directa al "precursor" argentino, la invitación a "violentar" la vida que Arlt propuso al cierre de los años 20. De hecho, Bolaño intensifica y concretiza la fusión entre el arte, la vida, la violencia y la muerte más allá de su condición de simulacro, para insertarla en la historia de dictaduras de América Latina y ponderarla desde una conciencia ética. Sostengo que es posible ver en Bolaño una realización literal, perfectamente enterada de sus excesos y peligros, de la estetización criminal de la vida prometida por Arlt: destaca en la narrativa del escritor chileno-español un gesto explicitador de los presupuestos arltianos, capaz de poner sobre el tapete la problemática intersección entre la literatura, la violencia criminal, la represión política y la misoginia que el proyecto vanguardista, tanto en América Latina como en Europa, puede fomentar en ciertas coyunturas, especialmente bajo un régimen fascista como el pinochetismo ${ }^{3}$.

2 En sintonía con Premat, Rocío Gordon propone redefinir el término "vanguardia" en Latinoamérica para desarrollar una noción más flexible y aplicable al presente, "en la cual la única dominante sea la eliminación de dominantes y la eliminación de centros" (144). Para Gordon, lo característico del texto vanguardista es el "giro estético" (129): una permanente capacidad de desestabilización. En estos términos, el giro estético del vanguardista Bolaño reside en su cuestionamiento ético de la centralidad de la violencia en la "vanguardia de la violencia" simbolizada por Arlt.

3 El vanguardismo de la violencia no es, ciertamente, el único que floreció en América Latina. El conflicto entre dos formas de vanguardia remite a la oposición entre "revolución" y "decadencia" señalada por José Carlos Mariátegui en un texto de 1926 ("Arte, revolución y decadencia"), indicando así la persistencia de una contradicción al interior del vanguardismo y las neovanguardias. Para Mariátegui hay dos clases de vanguardia: aquella que se contenta 
Existe pues, en Bolaño, una recuperación prudente de la vanguardia que, en ocasiones, linda con un temor a sus expresiones más tenebrosas. En efecto, la postura de Bolaño ante la escritura vanguardista lo sitúa en un linaje de escritores hispanoamericanos afectados, en mayor o menor medida, por esa condición que Aníbal González bautiza como "grafofobia", y que se origina en el poder letal de la escritura. En su visión de la vanguardia, Bolaño evidencia una actitud de reverencia y cautela, de atracción y repulsión, que suele despertarse ante lo abyecto, y que, como observa González, supone "an attitude towards the written word that mixes respect, caution, and dread with revulsion and contempt" (3). En América Latina, el miedo a la letra y sus oscuras energías tiene causas históricas pues nace de la imposición colonial de la ley y la cultura letrada sobre las civilizaciones indígenas; sin embargo, fuera del ámbito latinoamericano, se trata de una fobia ancestral, arraigada en la cultura occidental y en otras, a la profunda alteridad de la escritura. Un claro ejemplo de la grafofobia de Bolaño, dirigida en especial a la escritura de vanguardia, puede apreciarse en el miedo literal que manifiesta sentir hacia la novela Tadeys de Osvaldo Lamborghini, texto perverso que describe en su ensayo "Derivas de la pesada" como "una novela insoportable, que leo (dos o tres páginas, ni una más) sólo cuando me siento particularmente valiente" (Entre paréntesis 29$)^{4}$. La grafofobia no impide ni siega la escritura, sino que conduce a echar sobre ella una mirada recelosa, atenta a su potencial destructivo: este escepticismo, como señala también González, procede de Borges, "the touchstone for any discussion of writing and ethics in Spanish American literature in the latter half of the twentieth century" (90).

Por cierto, antes de iniciar una lectura conjunta de Bolaño y Arlt, es preciso hacer un desvío y pensar en el entronque más explícito de Bolaño con la tradición rioplatense: me refiero a la cuentística de Borges, a quien Bolaño consideraba "probablemente el mayor escritor que haya nacido en Latinoamérica" (Entre paréntesis 23), prodigándole una admiración no libre de fricción y crítica. Borges es, en todo caso, un referente imprescindible para el autor de "El gaucho insufrible";

con la renovación técnica (decadente) y aquella que busca una transformación utópica del orden burgués (revolucionaria) en alianza con la política radical. Mariátegui valida la vertiente revolucionaria, y culpa a Ortega y Gasset por haber restringido el arte nuevo al esteticismo decadente. La crítica hispanoamericana a Ortega pasa por la connotación negativa del término "deshumanización", al que se opone una necesidad de humanización, según se ve en otros textos como "Arte nuevo" de Martí Casanovas (Bosshard 28-29).

4 El ensayo "Derivas de la pesada" se encuentra recopilado en el volumen Entre paréntesis, editado por Ignacio Echevarría. De ahora en adelante, todos los ensayos que cite de Bolaño provendrán del mismo volumen. 
como sostiene Gustavo Faverón Patriau ("“6l rehacedor"), en este relato más bien largo y denso de Bolaño, en el que se expresa meridianamente su voluntad de reescribir la literatura argentina, coexisten ecos de cuentos de Santiago Dabove ("Ser polvo"), Julio Cortázar ("Carta a una señorita en París"), Antonio Di Benedetto ("Caballo en el salitral", "Aballay"), Juan Rodolfo Wilcock ("Los conejos") y Rodrigo Fresán ("Padres de la patria"), pero son sobre todo "El sur" y "El evangelio según Marcos" los textos que evidencian la conexión más vital con la historia del gaucho Juan Pereda. En cuanto a Estrella distante, es conocido que este texto supone una reescritura con ampliación de la reseña biográfica de Carlos Ramírez Hoffman al cierre de La literatura nazi en América, libro de vocación enciclopédica que deriva de la Historia universal de la infamia, el cual, a su vez, como el mismo Bolaño señala en su ensayo "El bibliotecario valiente", nace de Retratos reales e imaginarios de Alfonso Reyes y de Vidas imaginarias de Marcel Schwob (Entre paréntesis 290). Tanto en la Historia universal como en La literatura nazi emergen una estructura y un personaje que me parecen capitales para esta discusión: el clan de villanos, la comunidad de sujetos principalmente masculinos entregados al crimen y la violencia que, como sugiere González, delatan una atracción por la palabra y la ficción que los convierte en hermanos de sangre de los escritores ${ }^{5}$. La aparición de este protagonista colectivo no es casual ya que, como he sostenido en otro lugar (Castañeda, "Una dispersa dinastía de solitarios"), existe una vertiente del cuento borgeano cuyo núcleo es la sociedad secreta de autores, y que si bien tiene en "Tlön, Uqbar, Orbis Tertius" su ejemplo más citado, también aflora en "La secta del Fénix", "El inmortal", "Las ruinas circulares" y "La lotería de Babilonia", entre otros. La modulación más política y nefasta que adquiere en Borges la sociedad secreta se da con la representación del nazismo como una secta maldita. Así también en Bolaño: el hilo que enlaza nazismo, sociedad secreta, arte y violencia atraviesa la obra.

Ahora bien, me interesa señalar aquí que la presencia en Bolaño de sociedades secretas similares a las borgeanas, es decir intrínsecamente ligadas a la creación y la autoría (pensemos en el grupo poético de los realvisceralistas en Los detectives salvajes y el círculo de críticos en 2666), no responde a un diálogo exclusivo entre Bolaño y Borges, sino que brota de una relectura bolañesca del lugar 
del grupo, la comunidad, el cenáculo, en el panorama más vasto y abarcador de la vanguardia, en la cual el Borges de los años veinte es un actor central, como lo demuestra su papel en la revista Martín Fierro, pero sin duda no el único. Existen, pues, otros parentescos quizá menos nítidos entre Bolaño y la vanguardia argentina; en este punto, es necesario justificar la formación de la pareja Arlt/ Bolaño, dos figuras cuyas obras no parecen estar directamente conectadas y, más bien, podrían verse como distantes: así, de hecho, parece haberlas visto el mismo Bolaño. En "Derivas de la pesada" (Entre paréntesis 23-30), Bolaño identifica en Osvaldo Soriano, Arlt y Lamborghini las tres líneas principales de la literatura argentina post-Borges (o extra-Borges, cabría decir), manifestando hacia Arlt una valoración positiva que se ve empañada por el rescate pigliano del autor de Los siete locos, operación que a Bolaño le disgusta por parecerle que entraña una sobrevaloración. En todo caso, Bolaño pergeña un elogio matizado de Arlt, pero de ningún modo lo considera a la par de Borges; a la vez, arremete contra los tópicos de la lectura de Piglia, quien en su opinión desvirtúa a Arlt:

No puedo estar, de ninguna manera, a favor de los malos traductores del ruso, como le dijo Nabokov a Edmund Wilson mientras preparaba su tercer martini, y no puedo aceptar el plagio como una de las bellas artes. La literatura de Arlt, considerada como armario o subterráneo, está bien. Considerada como salón de la casa es una broma macabra. Considerada como cocina, nos promete el envenenamiento. Considerada como lavabo nos acabará produciendo sarna. Considerada como biblioteca es una garantía de la destrucción de la literatura. (Entre paréntesis 27-28)

Resulta claro que Bolaño no busca una filiación directa con el Arlt creado por Piglia, sino que marca su distancia frente a él, con lo cual leerlos en pareja supone, hasta cierto punto, observar a Arlt bajo una nueva luz. Si bien no existe entre estas obras un diálogo intertextual explícito, en el sentido que le atribuye Gerard Genette a la presencia de un texto dentro de otro (Allen 101), el vínculo inextricable entre el arte y la violencia surge en Arlt y en Bolaño como una preocupación cardinal, objeto de tratamientos intrigantemente análogos. Aunque es debatible situar en las novelas de Bolaño una intención autoral de reformular y debatir con los textos de Arlt, considero que resulta posible y digno de interés el proyecto de trazar conexiones en función de este factor común. En consecuencia, adopto aquí una concepción de la intertextualidad que, en la línea inaugurada por Roland Barthes con La muerte del autor (1968), privilegia al lector y a la lectura como instancias productoras de significado, capaces de visibilizar conexiones dentro de y entre los tejidos de citas que componen cada texto (Allen 75-76). Mi intención en 
las páginas siguientes es mostrar que la lectura cruzada de Arlt y Bolaño ilumina el asunto más global de la vitalidad de la vanguardia y la interpretación actual que de ella hacen los escritores del continente. Ciertamente, la dupla Arlt-Bolaño no excluye otras intersecciones de Bolaño con la tradición argentina: una lectura sin duda provechosa, y que también activa el puente entre violencia y vanguardia, es la que descubre la sombra de Lamborghini detrás de la efigie de Bolaño. En el mismo "Derivas sobre la pesada", Bolaño expresa, además de su miedo, su fascinación: "Con la obra de Lamborghini siempre me pasa lo mismo. No hay cómo describirla sin caer en tremendismos. La palabra crueldad se ajusta a ella como un guante. La palabra dureza también, pero sobre todo la palabra crueldad" (Entre paréntesis 29) ${ }^{6}$.

Volviendo a Arlt y sus cruces con Bolaño, mi reflexión en este artículo incluye un comentario sobre el carácter vanguardista del Club de ladrones de Silvio Astier en El juguete rabioso (1926); un análisis de la sociedad secreta del Astrólogo, Erdosain, el Rufián Melancólico y los otros en Los siete locos (1929)/ Los lanzallamas (1931) ; y, por último, una problematización de estas cuestiones a través del personaje de Carlos Wieder, el neovanguardista de ultraderecha que aparece en Estrella distante, novela de 1996. He seleccionado estos textos de Arlt

6 En las décadas de 1960 y 1970, la figura argentina que condensa tal vez mejor que ninguna la intersección entre vanguardia y violencia es la de Lamborghini. Miembro fundador de la revista neovanguardista Literal (1973), Lamborghini es ya un legendario "hijo bastardo" de la literatura argentina que, apartándose de la tutela de Borges, produce ficciones como su mítica opera prima El fiord (1969), que Susana Rosano define como "una especie de éxtasis sangriento, una forma de literatura snuff, compuesta por tormentos y torturas" (205). La ruptura del límite entre arte y vida a través del canal de la violencia adquiere en Lamborghini una modulación perversa y criminal que, de acuerdo con Gabriel Giorgi, siguiendo a Agamben en Homo sacer, consiste en la destrucción de los límites entre las fuerzas biológicas de la naturaleza y el ordenamiento social y político. Pero la cercanía entre la vanguardia y la violencia se puede rastrear más allá: también es ejemplar la novela La invención de Morel de Bioy Casares, en la que un grupo de amigos refugiados en una isla desierta recurren a la tecnología mortífera de una máquina productora de imágenes para generar una representación virtual de sí mismos. En la literatura actual, está el caso de Mario Bellatin, cuya emblemática novela Salón de belleza postula una comunidad de moribundos para cuya definición la belleza y la muerte son indesligables.

7 Considero que ambos textos forman un díptico porque poseen una trama única. El narradorcomentador enfatiza esta coherencia narrativa en la última nota al pie incluida en Los siete locos: "La acción de los personajes de esta novela continuará en otro volumen titulado Los lanzallamas" (Arlt, Obras 381). La estrategia de mantener intrigado al lector con promesas de continuación, para animarlo a adquirir un segundo libro, es una técnica del folletín, pero también de la publicidad: así, el narrador actúa como el promotor de un nuevo producto a través de sus notas, que funcionan como avisos publicitarios. 
porque en ellos se hace presente la violencia vanguardista como empresa colectiva y criminal. Por su parte, Estrella distante no es la única novela de Bolaño donde se explore este motivo, pues existen insinuaciones de la relación vanguardia/violencia en La literatura nazi en América, Nocturno de Chile, Los detectives salvajes y 2666. Sin embargo, Estrella distante resultar ejemplar porque se aboca íntegra y específicamente a reelaborar, politizar y deconstruir los principios de la vanguardia, tal como la practicaba el escritor argentino.

Como se sabe, el término "vanguardia" no fue utilizado por los vanguardistas para autodefinirse, sino que es una atribución hecha a posteriori desde el relato crítico (Bosshard 19). De igual manera, la inscripción de la obra de Arlt en el vanguardismo es un gesto de lectura que depende tanto del retrato que se dibuje del autor como de la definición de vanguardia en uso. Parto de una premisa de aceptación general que, para no desvanecerse en su vaguedad, debe ser contextualizada: el proyecto central de la vanguardia es la fusión del arte y la vida, proceso que puede ocurrir, en primer lugar, como una autocrítica de la institución europea del arte autónomo (esta es la visión de Bürger, centrada en el dadaísmo, el primer surrealismo y el futurismo). Pero también, en su versión latinoamericana, como un fenómeno estructuralmente original y diferenciado en el cual conviven impulsos contradictorios, como la apropiación cosmopolita de las tendencias europeas (Yúdice 53-54), el parentesco entre arte y activismo político (Unruh 7-8) y la reterritorialización de la alteridad indígena (Bosshard). Para hablar de vanguardia en la Buenos Aires de la década del 20, se suele hacer referencia a la pugna entre el esteticismo de Florida, asociado con el vanguardismo criollista y moderado del grupo Martín Fierro (Sarlo, "Vanguardia y criollismo" 49), y el realismo social de Boedo, de tendencia anarquista y base social inmigratoria. Arlt, que escapa a ambos polos, se instala en una "zona intermedia" (Viñas 11) del campo literario que le permite realizar una obra excéntrica y, además, contar con el patrocinio de Ricardo Güiraldes. Estéticamente distante tanto del realismo social, como del criollismo de figuras como Borges y el autor de Don Segundo Sombra (Gnutzmann 22-24, Romano 343, Rosenberg 49), Arlt produce un tipo de novela urbana en el que se puede reconocer, transfigurado y violentado, el llamado a fusionar arte y vida, pero desde una singularidad creativa que se interseca con lo más radical del arte europeo sin caer en una subordinación de la periferia al centro.

Es significativo que Arlt trabaje con otro mito clásico, muy presente en los cuentos de Borges sobre sociedades secretas como señalaba antes: el de "la vanguardia como etapa juvenil y grupal" (Premat 53). Valorar la energía resultante de un "estar juntos" transgresor, de una empresa comunitaria que es estética en sí misma - se estetiza un modo de socialización, por así decirlo— es imprescindible 
para descifrar la literatura de Arlt. En efecto, tanto en Los siete locos/Los lanzallamas, como en El juguete rabioso, la fusión del arte y la vida se experimenta grupalmente, en el seno de colectivos cerrados y clandestinos que remiten al círculo vanguardista y la célula revolucionaria: la sociedad secreta terrorista de Erdosain y el Astrólogo, y el Club de los Caballeros de la Media Noche de Silvio Astier. Estos colectivos funcionan como contra-espacios sociales de violación de toda norma donde los personajes "desertan del orden burgués" (Romano 346) y siguen gozosamente el rumbo del mal, camino que les infunde "una rara sensación de plenitud e incluso de omnipotencia" (Romano 346). Según Eduardo Romano, "a la juiciosa vida pública y al modelo de correcto ciudadano burgués contrapone Arlt las organizaciones para delinquir" (347).

Aunque a distinta escala, tanto la sociedad del Astrólogo, como el Club de Astier, que instalan su base de operaciones en la capital argentina, efectúan una transfiguración artística de sus actividades colectivas que implica una incursión en la criminalidad. La primera novela de Arlt, El juguete rabioso, es un bildungsroman de autoexilio social (Gnutzmann 35) protagonizado por Astier, alter ego de su autor y proveniente, al igual que él, de un trasfondo inmigratorio y una extracción social humilde. El primer capítulo, titulado "Los ladrones", parodia elementos de la tradición española áurea, entre ellos el personaje del Dómine Cabra en el Buscón de Quevedo (Gnutzmann 46), la novela ejemplar Rinconete y Cortadillo, y el episodio del cura y el barbero en el Quijote. Silvio, influido por sus lecturas de literatura bandoleresca, funda el Club con un grupo de muchachos amigos suyos. Si bien la práctica que realizan juntos es el robo, su objetivo no es utilitario. No se trata de adquirir bienes, sino de elevar el robo a la condición de acto estético, como razona el joven criminal: "No recuerdo por medio de qué sutilezas y sinrazones llegamos a convencernos de que robar era acción meritoria y bella" (Arlt, El juguete rabioso 97). La racionalidad de los fines queda anulada en favor de una exaltación de la acción en sí. El botín de los robos, el dinero, es sustraído al mundo de la actividad productiva, despojado de su valor como moneda y acariciado como un objeto hermoso, animado y sensorial, carente de valor de cambio y pletórico de valor de uso (o, más bien, valor de contemplación): "No era el dinero vil y odioso que se abomina porque hay que ganarlo con trabajos penosos, sino dinero agilísimo, una esfera de plata con dos piernas de gnomo y barba de enano, un dinero truhanesco y bailarín cuyo aroma como el vino generoso arrastraba a divinas francachelas" (105). La alusión al gnomo y al enano patentizan el carácter lúdico del robo, que se espacializa en la descripción de la guarida del Club, sitio donde se entrecruzan el juego, la lectura y la violencia: "Arrojados por los rincones había montones de títeres inválidos y 
despintados [...], cajas diversas con soldados de plomo atrozmente mutilados, hediondos bultos de ropa sucia y cajones atiborrados de revistas viejas y periódicos" (102). Cuando el Club gasta el dinero robado, lo hace para brindarse nuevas experiencias lúdico-estéticas análogas al robo, como los paseos en coche por una lluviosa Buenos Aires (100). El énfasis reside no en la finalidad, en el producto terminado, sino en un constante retorno al proceso, rasgo que Premat describe como (neo)vanguardista y sitúa en la continua productividad de la obra de César Aira (Premat 49).

Por ser un juego, el robo es una fuente de placer y una representación. El robo es concebido por el Club como un riesgoso y atractivo evento de gran intensidad emocional, capaz de producirles a sus participantes cierto deleite violento y memorable, como sugiere Silvio: "Aún no he olvidado la alegría que experimentaba al abrir las puertas" (Arlt, El juguete rabioso 98). Se trata de un autoconsciente disfrute de la transgresión, un "regocijo [que] nos engrandece las almas cuando quebrantamos la ley y entramos sonriendo al pecado" (111). Esta alegría teñida de peligro y evocada con grandilocuencia invoca, en palabras del mismo Silvio, la puesta en escena de un show teatral en el que los ladrones son actores desempeñando un exigente papel; un rol que implica una autodisciplina corporal masoquista: "Trabajábamos instigados de cierta jovialidad dolorosa, un nudo de ansiedad detenido en la garganta, y con la presteza de los transformistas en las tablas, riéndonos sin motivo, temblando por nada" (98). La teatralidad del evento enfatiza su relación con el arte y la literatura. Es significativo, por ello, que el gran golpe del Club se dé en una biblioteca de escuela de la que los ladrones buscan extraer tanto bombillas eléctricas como libros para construir su biblioteca "científica" (103). Sin duda, este episodio encierra una alegoría de los obstáculos de las clases populares argentinas de la época para acceder a la educación, pero además posee un carácter metaficcional que subraya su condición de reescritura quijotesca. La naturaleza estetizada o, en este caso, "literaturizada" del robo impregna el escrutinio conducido por Silvio, del cual se salvan textos de física, química, matemáticas y Las flores del mal (117). Así, la literaturización "maligna" de la experiencia domina el mundo ficcional.

De acuerdo con Vicky Unruh, es posible establecer una analogía entre el Club de Silvio y el prototipo del grupo vanguardista en la medida en que ambos afirman su superioridad espiritual en un mundo social prosaico y ordinario, pero además porque su carácter exclusivo es paradójicamente compatible con la aspiración más vasta de intervenir en la esfera pública - en El juguete rabioso, mediante el robo estetizado, que es secreto pero tienta siempre con publicarse y asombrar al buen burgués - y lograr la admiración de una audiencia masiva 
(Unruh 86). Para Silvio y sus compinches, este objetivo no llega a realizarse, pues el Club decide desintegrarse ante el temor de ser detenido por la policía, como tampoco se realiza su anhelo máximo: cometer un asesinato (Arlt, El juguete rabioso 106), deseo cuya sola idea suscita goce y que debe permanecer en la esfera de los simulacros. En realidad, el simulacro suplanta al referente: visto que se lo juzga superfluo, se decreta su eliminación ${ }^{8}$.

El propósito de intervenir radicalmente en la vida pública a través de una violencia siempre diferida, necesariamente imaginada, también nutre las aspiraciones de la sociedad secreta del Astrólogo. El Club de Astier comparte con ella la criminalidad, la voluntad de reproducirse en otros grupos asociados al original, y la condición anticipatoria y simulada de la experiencia estética. Liderado por Alberto Lezin - que remite a los modelos de Lenin y la revolución rusa-, el grupo que protagoniza Los siete locos/Los lanzallamas está compuesto no por personajes adolescentes dedicados al hurto menor, sino por adultos marginales decididos a ejecutar un proyecto distópico-totalitario de híbrida inspiración ideológica, suerte de parodia incoherente que amalgama los discursos fascista, comunista y capitalista (Kunheim 199). Su intención es emplear la violencia, en particular los ataques químicos con gas fosgeno, para tomar el poder en la Argentina y luego en el planeta, con el fin de implantar un orden mundial de amos y esclavos en el cual ellos, invirtiendo la actual jerarquía social, serán los todopoderosos. La naturaleza del proyecto es anticipatoria porque, al igual que los jóvenes ladrones que fantasean con el asesinato que jamás cometerán, el plan de la sociedad secreta se constriñe al discurso oral y al monólogo interior de los conjurados. Las sesiones de planificación colectiva y las fantasías personales producen, en términos de Baudrillard, un simulacro de distopía emancipada de un referente objetivo imposible.

8 Pese a la ruptura del grupo, Astier continúa poniendo en práctica los principios del vanguardismo criminal o violento en su biografía. Así, al final de El juguete rabioso, la traición contra el Rengo puede ser interpretada como un "encanallamiento" vanguardista capaz de producir sensaciones violentas que repercuten a largo plazo en la subjetividad de Silvio: “ ¿Por qué no? Entonces yo guardaré un secreto, un secreto salado, un secreto repugnante, que me impulsará a investigar cuál es el origen de mis raíces oscuras" (227). El motivo de la denuncia como acto maligno y placentero que se disfraza de acto moral está presente en el cuento "El indigno" de Borges, que entabla una relación intertextual con El juguete rabioso y ofrece una lectura análoga de la traición de Santiago Fischbein contra el compadre Ferrari (Gnutzmann 31-32). En la obra de Roberto Bolaño, existe una semejante prolongación individual de una ética juvenilgrupal perdida en el personaje de Arturo Belano, discípulo del vanguardismo realvisceralista (Castañeda, "Belano, Wieder y Reiter"). 
Significativamente, este referente liquidado no deja de evocar el que propuso la vanguardia histórica: la fusión del arte y la vida, ese objetivo utópico que, según Foster, reconoce y postula su infactibilidad como una crítica del status quo (16). El plan de la sociedad arltiana es, al igual que la fusión vanguardista, discursivo y performativo, en el sentido de que consiste menos en llevar a cabo la borradura literal del límite entre dos esferas que en "atacar" retóricamente los lenguajes artísticos de la época y en elaborar imágenes críticas de los insumos culturales disponibles (Foster 15-16): a fin de cuentas, esto es lo que hacen el Astrólogo, Erdosain y los otros al compendiar y transfigurar los discursos heterogéneos antes mencionados, entre los cuales conviven la ciencia y el milenarismo. El resultado es vanguardista en tanto que implica una transformación de la vida colectiva del cenáculo en un núcleo generador de delirios de destrucción y omnipotencia, que se despliegan como prodigiosos espectáculos de inspiración cinematográfica capaces de conmover y gratificar a los conjurados y sus futuros esclavos - la humanidad en pleno - tanto como la experiencia del robo sacude, a pequeña escala, a los camaradas de Astier:

La humanidad ha perdido sus fiestas y sus alegrías. ¡Tan infelices son los hombres que hasta a Dios lo han perdido! Y un motor de 300 caballos sólo consigue distraerlos cuando lo pilotea un loco que se puede hacer pedazos en una cuneta. El hombre es una bestia triste a quien sólo los prodigios conseguirán emocionar. O las carnicerías. Pues bien, nosotros con nuestra sociedad le daremos prodigios, pestes de cólera asiático, mitos, descubrimientos de yacimientos de oro o minas de diamantes. Yo lo he observado conversando con usted. Sólo se anima cuando lo prodigioso interviene en nuestra conversación. (Arlt, Obras 229)

Remo Erdosain (a quien se dirige el Astrólogo en la cita), uno de los subordinados de la sociedad secreta, es un inventor frustrado que fabrica un peculiar ornamento kitsch: la rosa de cobre, una flor natural metalizada por un proceso químico que metaforiza el estilo peculiar de vanguardismo arltiano: un vanguardismo de la violencia. En un acto a la vez criminal y filantrópico, Erdosain utiliza parte del dinero que ha robado de la compañía para la que trabaja con el objetivo de instalar un laboratorio galvanoplástico, taller dedicado a producir rosas de cobre en el hogar de una familia de burgueses empobrecidos a los que desea ayudar económicamente a través de la venta masiva de su invento (336). El sueño del enriquecimiento y el ascenso social a través de la ciencia y la técnica modernas contiene un elemento de lo "maravilloso moderno" (Sarlo, La imaginación técnica 73-77): la atribución de un poder mágico, capaz de estimular la imaginación 
colectiva y las ansias de reconocimiento de las clases populares, a la posibilidad de gestar artilugios mediante saberes transmitidos por las revistas de la época. Sin embargo, Erdosain y sus científicos amateurs apenas llegan a desarrollar un prototipo estéril que no se reproduce ni comercializa. La rosa permanece como una singularidad bella y desligada del mercado, que se limita a despertar el asombro de su pequeño círculo de creadores, pero sin rendirles un beneficio económico: "Remo examinó nuevamente la rosa de cobre, admirando su perfección. Cada pétalo rojo era casi transparente, y bajo la película metálica se distinguía apenas la forma nervada del pétalo natural, que había ennegrecido la cola" (Arlt, Obras 324). La rosa es presentada como una pieza artística autónoma que condensa, en forma y en materia, la cristalización no pragmática y efímera del saber técnico y la sensibilidad artística de Erdosain: su genio inconsecuente. El ascenso social continúa siendo un delirio no realizado que, al igual que la rosa misma, posee un valor estético intrínseco y una condición simulatoria, así como los hurtos del Club de Silvio Astier y la distopía planificada por la sociedad secreta.

En esa medida es posible considerar la rosa metalizada, literalmente una "flor del mal" de evidente resonancia baudelairiana, como un objeto ecfrástico que sintetiza las coordenadas específicas del proyecto de fusionar el arte y la vida en El juguete rabioso y Los siete locos/Los lanzallamas. La técnica artesanal, el robo adolescente y la conspiración terrorista constituyen actividades sin finalidad ulterior cuyo valor reside en la experiencia y en la (auto)contemplación de sus ejecutantes, que suplantan el lugar de la ganancia y del poder objetivos. La aparente heterogeneidad de estas prácticas no debe ocultar la homogeneidad de los practicantes, todos sujetos de clase baja con esperanzas de mejora socioeconómica, ni tampoco su inscripción en el mundo de la violencia y el crimen. En este universo, el dinero no sirve ya para calmar las urgencias materiales, pues su función es generar una belleza peligrosa, vinculada a la ilegalidad y la muerte. La rosa misma está muerta, como lo revela esta cita:

En el miserable cuchitril la maravillosa flor metálica esfoleaba sus pétalos bermejos. El temblor de la llama de la lámpara de acetileno hacía jugar una transparencia roja, como si la flor se animara de una botánica vida, que ya estaba quemada por los ácidos y que constituía su alma. (323)

La "botánica vida" es aparente: la estetización de la flor viva ha involucrado ejercer contra ella una violencia mortífera. Dicha violencia, mínima en la flor, se manifiesta en grados de intensidad galopante que transitan desde el microasesinato de la rosa hasta una envergadura inmensa: robar libros de una biblioteca escolar, defraudar a una compañía para financiar un laboratorio casero y una 
sociedad secreta, ejecutar a Barsut, desencadenar un ataque químico, y tomar el poder mundial, son eslabones de violencia organizados en un continuo ascendente que se va extremando, desquiciadamente, hasta alcanzar la destrucción de la raza humana.

La meta final, la conquista del poder, conlleva el montaje de un espectáculo del terror: los "prodigios" y las "pestes" (229) que planifica ofrecer el Astrólogo a los seres humanos remiten a la cercanía existente, en el imaginario de la cultura moderna desde el romanticismo hasta el presente, entre el artista de vanguardia y el terrorista. En Crimes of Art and Terror, Frank Lentricchia y Jody McAuliffe ilustran este nexo refiriéndose a un comentario del compositor Karlheinz Stockhausen tras el atentado contra el World Trade Center de Nueva York, el 11 de septiembre de 2001. Stockhausen calificó el acto terrorista como "the greatest work of art imaginable for the whole cosmos" (Castle), chocante declaración que le ganó una oscura celebridad mundial y el repudio de amplios sectores. Lentricchia y McAuliffe localizan en las palabras del músico alemán la reiteración de una analogía persistente en el arte occidental moderno, desde la poesía de Wordsworth hasta las novelas de Bret Easton Ellis, acerca del carácter metafóricamente "terrorista" de la aspiración estética del artista marginal a transformar la cultura, de manera absoluta y definitiva, a través de un shock brutal (Lentricchia y McAuliffe, 2-3). La proximidad entre el arte y el terrorismo no involucra exaltar como hazañas artísticas los actos del terrorista, operación deducible de las ambiguas palabras de Stockhausen, sino precisar un deseo artístico transgresor cuyo ideal simbólico de eficacia es la violencia espectacular y masiva del terror, capaz de violentar la conciencia de millones de espectadores simultáneamente. La voluntad de situarse fuera de la sociedad para, desde el margen, "bombardear" la esfera pública y la mentalidad burguesa es un anhelo de raíz romántica y de gran vigencia en la vanguardia de entreguerras que está presente en los conjurados de Arlt, tanto en El juguete rabioso como en Los siete locos/Los lanzallamas. En vista de que se trata de un topos de larga duración histórica, no sorprende verlo aflorar al otro extremo del siglo XX, en la obra de un autor tan atento a la tradición literaria latinoamericana y occidental - con especial predilección por el simbolismo francés y esa literatura del mal que epitomiza Baudelaire- como es Roberto Bolaño.

En más de una novela y poemario de Bolaño destaca la presencia de personajes que abrazan lo que se podría denominar una ética vanguardista; es decir, una marcada intención, en ciertos sujetos señalados, por anular la frontera entre su biografía y sus prácticas (pseudo)artísticas. Es digno de atención que esta ética esté vinculada, en menor o mayor grado, a la muerte y al mal (Castañeda, "Belano, 
Wieder y Reiter"), o a la barbarie (López-Vicuña). La misma es canalizada, en Los detectives salvajes, a través del grupo neovanguardista de los realvisceralistas, cuya concepción del vanguardismo tiene menos que ver con la producción de una obra poética que con la asunción de un vitalismo agónico, hasta cierto punto suicida - baste recordar el "sacrificio" de Cesárea Tinajero-, que culmina con la muerte de su líder, Arturo Belano. En 2666, es palpable la herencia vanguardista en el escritor alemán Benno von Archimboldi, autor de culto directa y, también, familiarmente ligado a la violencia a través de su participación en la Segunda Guerra Mundial y mediante su sobrino, Klaus Hass, primer acusado de los crímenes de Santa Teresa. En la misma novela póstuma existe un grupo análogo al cenáculo vanguardista: una comunidad de académicos europeos que persiguen los pasos del desaparecido Archimboldi, búsqueda que los pone en relación con una realidad sagrada que se esconde tras la presencia del autor. Es claro que la narrativa de Bolaño trasciende las fronteras geográficas y simbólicas del Cono Sur y de la literatura latinoamericana, exhibiendo una facilidad de tránsito permitida, según María José Bruña Bragado, por su emplazamiento biográfico e intelectual como un exiliado (43-44). Esta trascendencia global no obstaculiza, sin embargo, que Bolaño entre en diálogo con ciertos autores de la tradición latinoamericana. Es, concretamente, en Estrella distante donde se desarrolla con la mayor nitidez un "vanguardismo del mal" - y a la vez una crítica del mismo - que hunde sus raíces en los viejos experimentos de Arlt.

La conexión vanguardista entre el arte y la violencia es manifiesta en la narrativa de Arlt y Bolaño. En sus textos la vida, ampliamente entendida como el objeto de intervención de la acción artística - desde la rosa hasta la sociedad, pasando por el cuerpo humano-, llega a convertirse en arte gracias al contacto transformador, revolucionario y, muchas veces, mortal, de la violencia, entendida tanto literal como metafóricamente. La diferencia entre los autores es cualitativa, sin embargo, ya que, si bien en Arlt la violencia es principalmente verbal y simulada, en Bolaño se procede al cumplimiento del simulacro, cayendo en extremos repudiables de criminalidad que plantean interrogantes éticos mucho más perturbadores que los que suscita Arlt. Puede verse en Bolaño una realización neovanguardista, objetiva y sangrienta del proyecto de la vanguardia de los años veinte, proceso que le da la razón a Hal Foster en su apreciación del vínculo productivo entre vanguardia y neovanguardia. Una realización que se torna maligna y fatal puesto que, en Estrella distante, la estetización de la vida implica rescatar la tradición filosófico-literaria francesa del Mal representada por Sade y Bataille (Bruña Bragado 47). Dicha tradición se actualiza como una destrucción misógina del cuerpo femenino que termina siendo indesligable de la 
represión política pinochetista. En palabras de Jeremías Gamboa, que estudia el vanguardismo criminal de Carlos Wieder, el crimen es celebrado por el teniente de la Fuerza Aérea Chilena como una expresión artística:

La inscripción de rituales de tortura y asesinatos como elementos constituyentes de una representación simbólica que se puede reclamar artística $[\ldots]$ es el fruto de una lectura "al pie de la letra" de ciertas proclamas y fantasías de los movimientos más nihilistas de la vanguardia histórica: la erosión sin cortapisas de la división entre el arte y la vida como un modo de desbaratar la estetización del arte moderno y el ensalzamiento del crimen como una de las bellas artes. (217-218)

En la obra de Bolaño, el abyecto Wieder es una figura central porque fomenta una reflexión sobre los lazos entre el arte y la violencia y, en especial, sobre la glorificación de la violencia extrema que, según Lentricchia y McAuliffe, es esencial al arte moderno. El personaje de Wieder y sus "acciones" poéticas promueven, en el ámbito del Cono Sur, una relectura cuestionadora de proyectos violentistas como la sociedad secreta del Astrólogo, que en ningún momento enjuician su propia legitimidad, hecha a la luz de traumáticas realidades políticas que los problematizan, como la dictadura de Pinochet en Chile. Para Ignacio López-Vicuña, "[l]a voluntad revolucionaria de Wieder pone en escena los conceptos de violencia, destrucción y fundación de un nuevo orden, comunes a las vanguardias políticas y artísticas, pero trasmutados en una pesadilla que prefigura la violencia militar de las dictaduras militares del Cono Sur" (203). La existencia de esa perturbadora comunión entre vanguardia y dictadura, por más que sea en un espacio pesadillesco, conduce a relativizar el presupuesto humanista de que el arte y la literatura son influencias civilizadoras en la sociedad, y abre la perspectiva de que su misión se limite a una descorazonante exposición de la barbarie humana (López-Vicuña 199-202).

Estrella distante incorpora en el binomio vanguardia/violencia el componente político-nacional y, con él, los temas del fascismo y la opresión de género. Wieder, un joven ex-tallerista de poesía que durante el gobierno de Allende se hacía llamar Alberto Ruiz Tagle, busca alzarse como el neovanguardista oficial del régimen fascista de ultraderecha. Wieder cultiva su floreciente imagen pública montando espectáculos de aeropittura nacionalista que citan el belicismo futurista, parodian las intervenciones del C.A.D.A. y vaticinan, a través de una urticante parodia, la acción poética de Raúl Zurita en el cielo de Nueva York en 1982. Su "gran obra" es una exhibición/happening de fotografías de desaparecidos que son, en su mayoría, mujeres torturadas y asesinadas por el mismo 
Wieder - entre ellas las hermanas Garmendia, sus compañeras en los talleres de la juventud-, a la que asiste lo más granado de la élite militar. Interesantemente, en este evento se vislumbra una aplicación corporalizada, ejecutada "al pie de la letra" (Gamboa 217), del clásico procedimiento del "arte nuevo" bautizado por Ortega y Gasset como la "deshumanización". Refiriéndose a la realidad objetiva, o digamos aquí a la materialidad biológica del cuerpo humano, el artista "nuevo", según Ortega, "se ha propuesto denodadamente deformarla, romper su aspecto humano, deshumanizarla" (63). El lenguaje de Ortega contiene una metafórica violencia que, diluida por lo abstracto de su objeto, cobra densidad y humanidad en la novela de Bolaño. De la metáfora se pasa, por las retorcidas vías de una lectura perversa, al soporte humano, al lienzo del cuerpo, a las mujeres torturadas que ven atacada su humanidad y se ven a sí mismas cosificadas como objetos manipulables, pero aún vivos: "Las mujeres parecen maniquíes, en algunos casos maniquíes desmembrados, destrozados, aunque Muñoz Cano no descarta que en un treinta por ciento de los casos estuvieran vivas en el momento de hacerles la instantánea" (Bolaño, Estrella distante 97). Por cierto, es posible notar aquí un eco de las ficciones de ese autor que tanto miedo le provocaba a Bolaño, Lamborghini - particularmente, en El fiord - , en las que se experimenta brutalmente con "una naturaleza maleable, mutante, que el experimento quiere apropiar para, literalmente, rehacer los cuerpos" (Giorgi 241).

Vale la pena detenerse en la inquietante asimilación paródica entre Wieder y Zurita, los cuales, por sus posiciones de poder antagónicas bajo el pinochetismo, parecerían no ameritar comparación alguna. No obstante, Bolaño los hermana como dobles o siameses entre quienes la distancia supuestamente intocable entre el torturador y la víctima, entre el derechista y el izquierdista, se acorta para sugerir, con audacia y contra el sentido común, la connivencia entre la poesía - por más bienintencionada que esta sea- y la barbarie. Es claro que Bolaño sigue aquí el ejemplo de Borges en su Historia universal de la infamia, texto que, como vimos, establece una ecuación entre el escritor y el criminal, miembros de la misma especie con distintos grados de acercamiento a la violencia. Como indica Chiara Bolognese, incluso es dable referirse a un personaje único, "Wieder/Zurita" (259), quien no representa una pareja de opuestos; en realidad, Wieder y Zurita podrían entenderse como imágenes especulares, o como los distintos rostros de un solo ser complejo y monstruoso, creado por la vanguardia: "Con una finalidad irónica y de denuncia, Bolaño aproxima el arte vanguardista de la derecha a las hazañas de la izquierda neo vanguardista" (263). La parodia de Zurita entraña una punzante crítica: Bolaño deplora, en su ensayo "La poesía chilena y la intemperie", la "escatología" y el "mesianismo" de Zurita 
(Entre paréntesis 89), aludiendo tal vez a un absolutismo poético que critica, pero también refleja, la ideología fascista. Sin embargo, considero que es necesario despersonalizar la polémica entre Bolaño y Zurita, ya que esta no parece apuntar única o exclusivamente a una confrontación personal entre los dos escritores -la cual existe, según muestra Bolognese, y que Zurita continúa con su alusión a Bolaño en Cuadernos de guerra (Bolognese 265) -, sino a una intersección más general entre violencia y vanguardia, criminalidad y literatura.

Por otra parte, no es casual que la mayoría de las víctimas de Wieder sean mujeres: el dato pone en evidencia el "sexismo de estado" propio de los regímenes fascistas y el de Pinochet en concreto. A partir de 1973, el "enemigo interno" del estado pinochetista adquirió un rostro femenino, como sugieren María Elena Acuña Moenne y Matthew Webb: "Morover, constructing the 'enemy' as woman's body perpetuates the idea that the body of the other can be used, opened up, violated and disposed of" (159). En efecto, el régimen de Pinochet implementó una política de disciplinamiento del cuerpo femenino que compaginaba el uso estructural de la violación como método de tortura (151-154), con medidas pronatalistas como el desmantelamiento de los programas de planificación familiar de Allende y la criminalización del aborto $\left(154^{-160}\right)^{9}$. En este contexto, las acciones de Wieder no destacan, sino que parecen "normales" pues se adecuan a la regla oficial, con la salvedad de su posterior exposición como arte. Wieder procura estetizar y sublimar, entonces, ciertas prácticas de estado, intentando dotarlas de un aura artística que el "mal oficial", siguiendo el conocido argumento de Hannah Arendt, no tiene al ser puramente banal, mecánico y sistemático. Como plantea Carlos Burgos, "El pinochetismo o el videlismo y sus prácticas, más que la monstruosidad o el sadismo, son regímenes que necesitaron de la burocratización o sistematizaciones (ejecutadas por los más silvestres funcionarios) para llevar a

9 La violencia estructural contra la mujer no es la única forma de violencia institucional de género: en el Chile oficial de los años 70 y 80, misógino y homofóbico, el estado castigó a las comunidades LGBTQ con saña, condenándolas a la persecución, la prisión y la muerte, particularmente si sus miembros pertenecían a las clases menos favorecidas de la sociedad. Es solo a partir de la recuperación de la democracia en 1988 que las sexualidades no tradicionales empiezan a ganar visibilidad en la esfera pública, los medios de comunicación y la literatura (Blanco 153-570). En Estrella distante figura el personaje de Lorenzo, un chileno de extracción popular, marginalizado por su homosexualidad, que pierde los dos brazos en un accidente y, tras salvarse de un intento de suicidio, escapa del país y consagra su vida al arte. Es posible plantear una analogía entre los cuerpos femeninos desfigurados por Wieder y el cuerpo mutilado de Lorenzo; sin embargo, la diferencia entre ellos estriba en que Lorenzo actúa como una especie de $d a n d y$ vanguardista, quien al autoestetizarse se dota de la agencia necesaria para superar sus limitaciones físicas, generarse un espacio de autorrepresentación y elaborar un arte integral. 
cabo la desaparición de miles de personas" (134). Con lo cual Wieder "hace arte" utilizando una materia prima banal, banalidad que retorna sobre su producción para poner en duda su condición artística.

A pesar de la duda que envuelve el estatuto artístico de las creaciones de Wieder, lo cierto es que sus prácticas desnudan ciertas estructuras del arte, como ya vimos en el comentario sobre el gemelo Wieder/Zurita. Además de exponer la entraña patriarcal del régimen de Pinochet, la exhibición fotográfica de Wieder pone en evidencia las contradicciones de género que surcan en el arte moderno en su conjunto. El arte moderno es, después de todo, una institución dominada por la mirada masculina, en la que el cuerpo femenino asume la posición de la pieza artística. Por ejemplo, la alusión a los maniquíes literalmente "deshumanizados" por el torturador/artista remite, de manera directa, al caso paradigmático de la célebre y polémica obra del surrealista alemán Hans Bellmer. Las muñecas mutiladas de Bellmer, de miembros multiplicados y reorganizados como en un montaje, exasperan y explicitan, practican y (auto)denuncian, la dinámica de género hegemónica del vanguardismo histórico, cimentado por un deseo homosocial y una opresión de la mujer, según la formulación de Eve Kosofsky Sedgwick (1-20). En dicha dinámica, la perspectiva no neutra, sino predominantemente masculina y heterosexual del sujeto estético occidental, degradado a la posición de un bárbaro torturador, se proyecta sobre la figura femenina para distorsionarla y desfigurarla (Lev, 475-476), o deshumanizarla a la manera de Ortega y Gasset. También es posible detectar este privilegio epistemológico en Arlt: las organizaciones y sociedades secretas de El juguete rabioso y Los siete locos/Los lanzallamas, aunque no dirijan su actividad criminal contra sujetos femeninos cosificados/victimizados, se revelan como grupos de composición abrumadoramente masculina donde la virilidad está ligada al ejercicio de un poderío violento, y a la capacidad de dominación y agresión tanto retóricas como físicas ${ }^{10}$.

La autoexhibición brutal y desafiante de la "autoría" de sus crímenes realizada por Wieder, quien firma sus obras sin ocultarse, suscita el rechazo hipócrita

10 Jill S. Kunheim realiza un estudio de las masculinidades presentes en el díptico arltiano y concluye que su representación es compleja: por una parte, Erdosain simboliza una "anti-masculinidad" feminizada y masoquista en la que la frustración sexual y la masturbación desnudan la subordinación del personaje; sin embargo, Erdosain todavía está integrado a la economía patriarcal de la sociedad secreta (118-122). Por su lado, el Astrólogo ofrece un modelo de masculinidad más convencional, basado en la manipulación retórica de sus subordinados: el hecho de ser un castrado no le impide ser "el centro del poder fálico" (122). En cuanto a los personajes femeninos, el más complejo es Hipólita (Kunheim 123), la ex-prostituta que constituye junto al Astrólogo una familia alternativa, alcanzando un poder cercano al suyo. 
del poder oficial. Lejos de triunfar como el artista de un régimen que se maquilla y esconde sus abusos, Wieder desaparece de la escena chilena y se exilia en Europa, donde se suma a empresas neovanguardistas que el narrador de Estrella distante, su ex-compañero juvenil, presenta bajo el signo del agotamiento y el envilecimiento, como la "escritura bárbara". Es significativo que Raoul Delorme, teórico del movimiento bárbaro, describa su propósito como una "humanización" del libro: mediante los actos de orinar, defecar y masturbarse sobre los clásicos de la literatura, se persigue una compenetración física con ellos y una asimilación del libro al cuerpo (Bolaño, Estrella distante 139-140). La humanización del libro es el reverso de la deshumanización del cuerpo practicada por Wieder cuando aún estaba en Chile: en ambos casos, se trata de acciones literales y efectivas, experiencias que no permanecen en el ámbito del simulacro, como el asesinato para Astier y los ladrones juveniles, o como la fundación de la distopía para la sociedad secreta del Astrólogo. La alusión al carácter "bárbaro" de las nuevas actividades de Wieder hace resonar ese otro significado de "barbarie" como el lado salvaje y sangriento de la humanidad que, según López-Vicuña, le toca desnudar al arte: Wieder, no obstante, no desnuda sino que predica y propaga la barbarie.

En este punto es imperativo aclarar que el hecho de que Wieder practique una versión rebajada de vanguardismo no cancela a la neovanguardia en pleno, sino que permite ver la distancia que siempre existió entre los crímenes del aviador y un arte realmente valioso y renovador, no imitativo ni desvirtuador. El reciclaje kitsch está presente desde las primeras exhibiciones aéreas de un criminal disfrazado de artista que fracasa en camuflar sus horrendos delitos utilizando la coartada de la estética, o escudándose en la cercanía - que no es lo mismo que una identidad total—entre el criminal y el escritor. Analizando la inscripción de Wieder en el movimiento bárbaro, es posible darle la razón a Bürger cuando se refiere al final de la vanguardia, pero no por su degeneración comercial, sino por efecto de la repetición vacía, involuntariamente autoparódica, de modelos previos, en este caso de los quehaceres pasados de Wieder. Sin embargo, Wieder deconstruye el modelo de Bürger según el cual existiría un origen fecundo y un agotamiento posterior del vanguardismo, ya que las acciones del joven Wieder, lejos de ser experimentos originales, eran ya copias del futurismo y anticipos desviados del activismo neovanguardista chileno. Irónicamente, "la vanguardia como etapa juvenil y grupal" (Premat 53), como periodo de inusual actividad galvanizada por la energía colectiva, no ocurre para Wieder, el falso artista que traiciona a sus compañeros de taller: su poesía y su activismo, desde la juventud hasta la adultez, son siempre trasnochados, no ofrecen más que pseudoarte, porque ocurren a la retaguardia de la historia. Wieder, en conclusión, 
no es un poeta, sino que refleja el lado más oscuro de la poesía: concentra sus sombras sin negar la validez de sus luces.

El cruce entre violencia y vanguardia, que tanto Arlt como Bolaño tienen gran interés en escenificar, como he mostrado hasta aquí, no nace en el vacío ni supone una mera coincidencia, sino que responde a la encrucijada históricocultural en que surgió el arte moderno, con el cual la literatura latinoamericana entabla un diálogo en pie de igualdad. Como sabemos, no se puede describir este diálogo como una conversación entre centro y periferia, oposición deconstruida desde los albores del siglo XX por la simultaneidad de los fenómenos artísticos asociados al modernismo (Geist y Monleón xxviii-xxix). Por el contrario, Bolaño, como autor global que supera y hace crecer el paradigma del escritor latinoamericano tradicional, permite releer a Arlt como otro creador capaz de escapar del caparazón local-regional para entrar en debates de más amplio alcance. Pues bien, en este caso el debate consiste en determinar el origen de la violencia que se cuela en las novelas estudiadas en este artículo, pero que las sobrepasa y forma parte de una estructura cultural mayor. En su ensayo Bluebeard's Castle, George Steiner señala que la cultura europea del temprano siglo XX, en la que el fascismo llegó al máximo poder político, detentaba una obsesión con la violencia y un apetito de destrucción interpretables como una reacción de hartazgo ante el ennui del siglo XIX. Esta reacción anti-pacifista se plasmó en una literatura insuflada de insatisfacción y de un virulento deseo de transformar la vida ordenada, pacífica y civilizada del "jardín de la cultura liberal" (Steiner 5) europea que floreció hasta la ruptura del orden que supuso el sanguinario período de guerras entre 1914-1945. Las guerras mundiales, así, vienen a atender las plegarias de devastación, constituyendo una nefasta profecía autocumplida, de un modo análogo a aquel en que la obra de Bolaño viene a realizar las fantasías y delirios insinuados por Arlt.

Señala Burgos que "[l] a vanguardia quiso reformar el mundo, pero también muchas veces quiso higienizarlo. En su deseo de quebrar las restricciones del mundo, no pocas veces se escondió un gesto autoritario y violento" (131). En un medio cultural europeo enamorado de la violencia, es imposible negar la existencia de una colusión entre el fascismo y el arte vanguardista, como lo demuestra el apoyo de Joseph Goebbels y otras figuras claves del Tercer Reich al expresionismo, y la militancia de artistas como Emil Nolde en las filas del nazismo (Antliff 148). En Italia, es sintomática la política cultural de Benito Mussolini, promotor de movimientos como el racionalismo arquitectónico y el futurismo (Antliff 148). Todo ello no es inusitado: como sostiene Mark Antliff, ciertos valores centrales del arte moderno, como el regeneracionismo, el espiritualismo, el primitivismo y 
el irracionalismo, fueron integrados en la matriz ideológica del fascismo, el cual fue capaz de encontrarlos compatibles y de absorberlos a pesar de su progresismo por la misma naturaleza contradictoria del fascismo: reaccionaria y antimoderna por un lado, y por otro proclive a abrazar la tecnología y los nuevos avances para acrecentar su poder (148-149). Violencia, vanguardia y fascismo están hermanados desde el nacimiento del siglo XX.

La yuxtaposición fascista de paradigmas en conflicto como el anhelo de retornar a un pasado mítico, y el de construir un futuro híper-moderno e industrializado, se encuentra en el díptico de Arlt. Es verdad, pues, que el plan de la sociedad secreta conjuga un retorno a la servidumbre feudal que no está reñido con el uso de la ciencia y la técnica, desde el cine hasta la química. Ciertamente, existen pocas novelas latinoamericanas en mostrar de modo tan abierto como Los siete locos/Los lanzallamas, caso inusual y extremo en el contexto del vanguardismo "rehumanizado" de América Latina, el poder de seducción de la violencia investigado por Steiner en la realidad europea. El texto de Arlt ilumina, a través del proyecto estético-político del Astrólogo, no solo la compatibilidad sino la imbricación del fascismo, la vanguardia y la violencia, pero no se detiene a reflexionar sobre las potenciales consecuencias de esa peligrosa fórmula. Setenta años después, la historia y sus horrores a nivel mundial y latinoamericano se encargarían de propiciar un examen lúcido de la fascinación vanguardista con la oscuridad del ser humano, manifiesta en los delirios de aniquilación de los "demonios" arltianos, desde una óptica menos complaciente. La obra de Bolaño moviliza, además de una reescritura y un homenaje paródico, una toma de autoconciencia ética de la vanguardia latinoamericana, realizada en su etapa neovanguardista de fines del siglo XX, frente a su propia historia y literatura, operación que supone tanto una inscripción en la tradición, como una revitalización cautelosa del legado de escritores como Arlt.

\section{Obras citadas}

Acuña Moenne, María Elena, y Matthew Webb. "Embodying Memory: Women and the Legacy of the Military Government in Chile". Feminist Review 79 Latin America: History, war and independence (2005): 150-161. Impreso.

Allen, Graham. Intertextuality. Londres y Nueva York: Routledge, 2000. Impreso.

Antliff, Mark. "Fascism, Modernism, and Modernity". The Art Bulletin 84.1 (2002): 148169. Impreso.

Arlt, Roberto. El juguete rabioso. Ed. Rita Gnutzmann. Madrid: Cátedra, 2011. Impreso. Obras. Tomo I. Novelas. Buenos Aires: Losada, 2008. Impreso.

Baudrillard,Jean. Cultura y simulacro. Trad. Pedro Rovira. Barcelona: Editorial Kairós, 1978. Impreso. 
Blanco, Fernando. "Sexualidades en transición: Homografías post Pinochet". INTI, Revista de literatura hispánica 69/70 Chile en su literatura (1973-2008) (2009): 15317o. Impreso.

Bolaño, Roberto. Entre paréntesis: ensayos, artículos y discursos (1998-2003). Ed. Ignacio Echevarría. Barcelona: Anagrama, 2012. Impreso. Estrella distante. Nueva York: Vintage Español, 2010. Impreso. La literatura nazi en América. Barcelona: Seix Barral, 2008. Impreso. Los detectives salvajes. Barcelona: Anagrama, 2005. Impreso. 2666. Barcelona: Anagrama, 2004. Impreso.

Bolognese, Chiara. "Roberto Bolaño y Raúl Zurita: referencias cruzadas". Anales de la literatura chilena 11 (2010): 259-272. Impreso.

Borges, Jorge Luis. "El indigno". Obras completas 1952-1972. Ed. Sara Luisa del Carril. Buenos Aires: Emecé, 2005. 435-439. Impreso. Historia universal de la infamia. Obras completas 1923-1949. Ed. Sara Luisa del Carril. Buenos Aires: Emecé, 2005. 305-367. Impreso.

Bosshard, Marco Thomas. La reterritorialización de lo humano: una teoría de las vanguardias americanas. Pittsburgh: Instituto Internacional de Literatura Iberoamericana, 2013. Impreso.

Bruña Bragado, María José. "El poeta-detective-asesino, personaje recurrente y alter ego en la narrativa de Roberto Bolaño". Roberto Bolaño, estrella cercana: ensayos sobre su obra. Eds. Augusta López Bernascocchi y José Manuel López de Abiada. Madrid: Editorial Verbum, 2012. 41-55. Impreso.

Bürger, Peter. Teoría de la vanguardia. Trad. Tomás Joaquín Bartoletti. Buenos Aires: Las cuarenta, 2009. Impreso.

Burgos, Carlos. "Roberto Bolaño: la violencia, el mal, la memoria". Nuevo texto crítico 22.42/43 (2009): 123-144. Impreso.

Castañeda, Luis Hernán. "Belano, Wieder y Reiter: tres autores malditos en las novelas de Roberto Bolaño". Libros \& Artes, Revista de la Biblioteca Nacional del Perú XI.60-61 (2013): 32-35. Impreso. "Una dispersa dinastía de solitarios: la sociedad secreta en los cuentos de Borges". Variaciones Borges 32 (2011): 179-200. Impreso.

Castle, Terry. "Stockhausen, Karlheinz. The Unsettling Question of the Sublime". New York Magazine, 27 agosto 2011. Web. 18 agosto 2014.

Contreras, Sandra. Las vueltas de César Aira. Rosario: Beatriz Viterbo, 2002. Impreso. Faverón Patriau, Gustavo. "El rehacedor': ‘El gaucho insufrible’ y el ingreso de Bolaño en la tradición argentina". Bolaño salvaje. Eds. Gustavo Faverón Patriau y Edmundo Paz Soldán. Barcelona: Editorial Candaya, 2008. 371-415. Impreso. 
Foster, Hal. The Return of the Real: The Avant-Garde at the End of the Century. Cambridge/Londres: The MIT Press, 1996. Impreso.

Gamboa,Jeremías. " ¿Siameses o dobles? Vanguardia y postmodernismo en Estrella distante de Roberto Bolaño". Bolaño salvaje. Eds. Gustavo Faverón Patriau y Edmundo Paz Soldán. Barcelona: Candaya, 2008. 211-236. Impreso.

Geist, Anthony L., y José B. Monleón. "Introduction. Modernism and its Margins: Rescripting Hispanic Modernism". Modernism and its Margins: Reinscribing Cultural Modernity from Spain and Latin America. Eds. José B. Monleón y Anthony L. Geist. Londres/Nueva York: Garland Publishing, 1999 . xvii-xxxv. Impreso.

Giorgi, Gabriel. "El crimen, el experimento, la literatura: Osvaldo Lamborghini y la naturaleza". Y todo el resto es literatura: ensayos sobre Osvaldo Lamborghini. Eds. Natalia Brizuela y Juan Pablo Dabove. Buenos Aires: Interzona, 2008. 233-253. Impreso.

González, Aníbal. Killer Books: Writing, Violence, and Ethics in Modern Spanish American Narrative. Austin: University of Texas Press, 2001. Impreso.

Gordon, Rocío. "Repensando las primeras vanguardias del Cono Sur más allá del 'gesto': Juan Emar, Felisberto Hernández y Macedonio Fernández". Estar en el presente: literatura y nación desde el bicentenario. Eds. Enrique Cortez y Gwen Kirkpatrick. Berkeley/Lima: Centro de Estudios Antonio Cornejo Polar/ Latinoamericana editores, 2012. 127-146. Impreso.

Gnutzmann, Rita. Introducción. Prefacio. El juguete rabioso. Por Roberto Arlt. Ed. Rita Gnutzmann. Madrid: Cátedra, 2011. 9-83. Impreso.

Kunheim, Jill S. “Arlt: masoquismo y estado". Hispamérica 28.83 (1999): 117-124. Impreso.

Lentricchia, Frank, y Jody McAuliffe. Crimes of Art and Terror. Chicago/Londres: University of Chicago Press, 2003. Impreso.

Lev, Leora. "'Tis Pity she's a Corpse: Modernism, Remembering, and Dismemberment in Valle-Inclan's Sonatas". Revista Canadiense de Estudios Hispánicos 24.3 (2000): 473-490. Impreso.

López-Vicuña, Ignacio. "Malestar en la literatura: escritura y barbarie en Estrella distante y Nocturno de Chile de Roberto Bolaño". Revista Chilena de Literatura 75 (2009): 199-215. Impreso.

Mariátegui, José Carlos. "Arte, revolución y decadencia". Direcciones del vanguardismo hispanoamericano: estudios sobre poesía de vanguardia en la década del veinte.

Ed. Gloria Videla de Rivero. Pittsburgh: Instituto Internacional de Literatura Iberoamericana, 1994· 319-320. Impreso. 
Ortega y Gasset, José. La deshumanización del arte y otros ensayos de estética. Madrid: Editorial Espasa Calpe, 2005. Impreso.

Premat, Julio. "Los relatos de la vanguardia o el retorno de lo nuevo". Cuadernos de literatura XVII.34 (2013): 47-64. Impreso.

Romano, Eduardo. "Arlt y la vanguardia argentina". Las vanguardias literarias en Argentina, Uruguay y Paraguay: bibliografía y antología crítica. Eds. Carlos García y Dieter Reichardt. Madrid: Vervuert Iberoamericana, 2004. 343-349. Impreso.

Rosano, Susana. "El arte como crueldad". $Y$ todo el resto es literatura: ensayos sobre Osvaldo Lamborghini. Eds. Natalia Brizuela y Juan Pablo Dabove. Buenos Aires: Interzona, 2008. 201-214. Impreso.

Rosenberg, Fernando J. The Avant-Garde and Geopolitics in Latin America. Pittsburgh: University of Pittsburgh Press, 2006. Impreso.

Sarlo, Beatriz. La imaginación técnica: sueños modernos de la cultura argentina. Buenos Aires: Nueva Visión, 1992. Impreso.

"Vanguardia y criollismo: la aventura de Martín Fierro". Revista de crítica literaria latinoamericana 8.15 (1982): 39-69. Impreso.

Sedgwick, Eve Kosofsky. Between Men: English Literature and Male Homosocial Desire. New York: Columbia University Press, 1992. Impreso.

Steiner, George. In Bluebeard's Castle: Some Notes towards the Redefinition of Culture. New Haven: Yale University Press, 1973. Impreso.

Unruh, Vicky. Latin American Vanguards: The Art of Contentious Encounters. Berkeley/ Los Angeles: University of California Press, 1994. Impreso.

Viñas, David. "Trece recorridos con las novelas de Arlt". Obras. Tomo I. Novelas. Ed. David Viñas. Buenos Aires: Losada, 2008. 7-32. Impreso.

Yúdice, George. "Rethinking the Theory of the Avant-Garde from the Periphery". Modernism and its Margins: Reinscribing Cultural Modernity from Spain and Latin America. Eds. Anthony L. Geist y José B. Monleón. Nueva York/Londres: Garland Publishing, 1999.52-80. Impreso. 